\title{
What Do Emotions Do? A Pragmatist Approach to the Role of Emotions in Media Events
}

\begin{abstract}
Jocelyne Arquembourg
Sorbonne Nouvelle University

Expressions of emotion in the media, especially in the context of news, are often criticized as promoting irrational attitudes. For supporters of this kind of criticism, rather than addressing such emotional sensitivity, journalism should be objective, appealing to the rationality of the public. Anger, indignation, enthusiasm, and expressions of joy or sadness should not have part in public debates. From this perspective, rationality and emotions are opposed, the former being fundamental for the constitution of the public sphere, while the latter falls into the category of inner impulses. While Kant denied any sort of rationality to emotions, Gustave Lebon attributed emotional attitudes to crowds rather than to a public. In a crowd, emotions spread like an epidemic through a kind of contagion. The present study is based on a contrasting perspective and focuses on the rationality of emotions, whether in philosophy (Nussbaum), sociology (Paperman, Aranguren 2014; Livet 2002), or psychology (Kraut-Gruber). Oddly enough, these different approaches do not seem to have affected media studies where, belief in the irrationality of emotions, still dominates analyses of media coverage of natural or industrial catastrophes, wars, or terrorist attacks. Instead of considering the nature of emotions, or the question of whether they actually corrupt the objectivity of journalism and the supposed rationality of public debates, I will seek to develop a pragmatist approach to the question of what, emotions actually do. In fact, the idea of emotions spreading contagiously had been disputed since the 18th century when Adam Smith asked how a British newspaper reader could be affected by an earthquake happening in China. Suffering from a distance, says Adam Smith, is not the product of some kind of contagion. If we want to understand this sort of feeling, we have to imagine an inner moral spectator inside of every human being. Oddly enough, Adam Smith considers emotions to be moral feelings. To feel horrified by the consequences of an earthquake, or to feel indignant about the death of innocent victims, are moral attitudes. In this respect, they are rational, but the feelings of indignation or horror also include bodily reactions. We scream, put our hands over our mouths; we blush, have tears in our eyes; we feel our heartbeat accelerate etc. These bodily reactions seem impulsive and entirely subjective, but to what extent can we say that they are rational or moral?
\end{abstract}

Keywords: emotion, pragmatist approach, media

\section{What is Happening When We Are Frightened by a Bear?}

This odd question is the subject of an extended correspondence between William James and Charles Sanders Pierce. The latter has studied emotions throughout his life, and although his commentaries are spread through many papers, he returns often enough to the question to produce a relatively substantial body of work.

Jocelyne Arquembour, professor, directress, Sorbonne Nouvelle University, France; main research field: Information and Communication Sciences. 
David Savan has gathered and astutely analyzed these various texts and most of his conclusions have been developed and commented upon by Robert Beeson in his doctoral thesis entitled: "Peirce on the Passions: The Role of Instinct, Emotion and Sentiment in Inquiry and Action.” Aside from Charles Sander Peirce's work itself, I will refer frequently to these two pieces in what follows.

The context in which Peirce and other pragmatists such as James develop their views of emotions is deeply influenced by Darwin and the evolution theory. For James, emotions originate from the body and are not mental states; they are physical responses to sensations "Our natural way of thinking about these standard emotions," says James, in Essays in Psychology:

is that the mental perception of some fact excites the mental affection called the emotion, and that this latter state of mind gives rise to the bodily expression. My thesis, on the contrary is that the bodily changes follow directly the perception of the exciting fact, and that our feeling of the same changes as they occur is the emotion. Common sense says: we lose our fortune, are sorry and weep; we meet a bear, are frightened and run; we are insulted by a rival, are angry and strike. The hypothesis here to be defended says that this order of sequence is incorrect, that the one mental state is not immediately induced by the other, that the bodily manifestations must first be interposed between, and that the more rational statement is that we feel sorry because we cry, angry because we strike, afraid because we tremble, and not that we cry, strike or tremble because we are sorry, angry or fearful, as the case may be. Without the bodily states following the perception, the latter would be purely cognitive in form, pale, colourless, destitute of emotional warmth. We might then see the bear and judge it best to run, receive the insult and deem it right to strike, but we could not actually feel afraid or angry. ${ }^{1}$ (1884, 188-205)

When he states that the "bodily changes follow directly the perception of the exciting fact," James reduces the emotions to physical movements which occur in the same way as physical reflexes. First, emotions are defined as the sensations of a physical change, in which case they appear to be no more than an automatic response to a perception. There is no room for interpretation or any kind of mental activity between the perception and the physical change. Yet one may wonder whether an encounter with a bear produces the same physical changes in someone who is peacefully hiking around the mountains and in a bear hunter. In place of the fear experienced by the hiker, the hunter may feel excitement and a sense of power. The physical change thus seems to depend on the evaluation of a situation: Purpose, agency, motivations, circumstances, and means are among the various elements at play in this situation.

Peirce considers James's example of the encounter with a bear but arrives at a very different conclusion. He uses the same example to develop another theory of emotions, based on his theory of signs and phaneroscopic categories. Peirce gives a much more important and complex role to emotions. First, he observes that if the bodily manifestations determine emotions, it must be difficult to distinguish between tears caused by joy or sadness. It is hardly possible to categorize an emotion as being of a certain type based on physical manifestations alone. There must be a part of interpretation wherein we attribute our tears either to joy or sadness. Peirce also remarks that if the body reacts to a perception, it seems to react to the initial "feeling-quality" of an object or a situation (Firstness). But, in reality, he argues that the quality of a situation is never a first impression, or if it is, it occurs before any attempt to define such a quality. Defining the quality of a situation requires the mediation of a concept. When we say, for instance, that an oven is black, we appear to express a first impression, but actually, "it is black" refers to a concept of blackness which can be applied to many other objects such as the frying pan on the oven, or the cat purring beside the oven. It is the same with emotions. To feel that we are happy, we need a concept of happiness which we can apply to a meeting with a friend, good news, a successfully written exam as well as the sight of a beautiful landscape etc. Peirce's 
criticism of James aims to demonstrate that emotions cannot be considered as direct reactions to a perception and that perceptions themselves are mediated by concepts of some kind (Thirdness). In the example of the encounter with a bear, there must be a concept of danger that can be applied to the situation which will not have the same effect on the hiker and the hunter. In fact, what Peirce wants to show is that emotions should be considered as signs, which play a role in individual's evaluation of their situations and environments as well as in their interactions.

\section{Emotions as Signs}

What does it mean to say that emotions are signs? First of all, just as saying that an oven is black necessarily involves the mediation of a concept, the capacity to name an emotion requires concepts of joy, indignation, sadness, horror, etc. David Savan remarks that: "Emotions do recur. My revulsion at torture is the same today as it was yesterday. To compare two temporally distinct occurrences, they must be brought together set side by side, and this can happen only if the two occurrences are represented. An emotion is then, a representamen, a sign” (319-33). ${ }^{2}$ Following Peirce, a sign is composed of a representamen, an object and an interpretant. Emotions always have an object:

If a man is angry, he is saying to himself that this or that is vile or outrageous. If he is in joy, he is saying "this is delicious." If he is wondering, he is saying "this is strange.” In short, whenever a man feels, he is thinking of something. Even those passions which have no definite objects—as melancholy—it only comes to consciousness through tinging the objects of thought. ${ }^{3}$ (5.292)

Consequently, emotions are signs whose objects are situations and when we need to determine our emotions, we need the mediation of a concept to identify them. This process has two faces depending on whether we attempt to determine our own emotion or another's emotions. The example of the encounter with a bear is an attempt to define the process of the emotions that we experience. More often our emotions are intertwined with social interactions. When we see someone else blushing or becoming suddenly pale, crying, or laughing, we identify what they are feeling and we treat these outwards signs as indices (in the Peircean sense) of a specific type of emotion. Indices link a first and a second object in various activities such as fight, love, work, etc. The term "index" (alternatively used by Peirce instead of "indice") usually refers to an object in the outer world, such as an index finger pointing toward something, or the grammatical demonstrative "this" or "that." These signs are affected by that their object in the way a weather vane is affected by the wind or a foot-print in the sand is by a foot, and we consider other people's signs of emotions as symptoms and diagnose their emotions on that basis. As far as bodily reactions are concerned, emotions occur when individuals are affected by their environment. Some years after Peirce, John Dewey says that emotions are a transaction between an organism and its environment (Dewey 2011; Aranguren 2014). As bodily reactions, they are reactions to an environment, and can give rise to specific behaviors in response. When a baby cries, his mother may interpret the crying as an indication that the baby is hungry or that something is causing him discomfort. She then acts in order to change the conditions which have given rise to the baby's cries by feeding him, changing him, or trying to find what is causing him discomfort. As the baby grows up, he becomes aware of an existing relationship between his cries and his mother's response. He then might cry intentionally in order to make his mother come to him. In this case, the cry is intentional and like a linguistic sign (i.e., a symbol); it is used to inform or communicate. It is no longer the sign of a "feeling" but rather a sign used intentionally to give rise to a specific response. Thus emotions are ambiguous signs, as an indice that they give evidence of how we evaluate a situation but they can 
also be used as symbol in human communication.

At the same time, and contrary to William James, the transaction between an organism and its environment is never direct but conveys a conceptual mediation which refers to the role of an interpretant. There can be three different types of interpretants: dynamic, energetic, and logical. On the whole, the interpretant of an emotion is its effect, but there can be different sorts of effects. Following David Savan,

First, the emotional dynamic interpretant is the qualitative semiotic effect of that sign; second, the dynamic interpretant may be an act in which some energy is expended, and such an act Peirce called an energetic interpretant. The energetic interpretant may be a muscular encounter with the external world, or it may be the manipulation and exploration of the images of the inner world... The logical dynamic interpretant is the thought, concept, or general understanding actually produced by a sign. To think is to make inferences, to draw on consequences of certain premisses, to move in accordance with some general rule. ${ }^{4}(1987-1988,48)$

Peirce insists on the dynamic aspect of the interpretant which plays an important part in the dynamic of a situation. It may have one or more of the three following characteristics: If we tremble or cry or laugh, when facing a situation or an event, we feel the qualitative effect of a situation. Now, if we run, upon encountering a bear, this is an energetic interpretant; if we look for a rifle and aim at the bear, or if we look for a place to hide, these are logical interpretants. But, within the dynamic of the interpretants, we may possibly scream, then run and still eventually look for a place to hide. These three dimensions of the sign allow us to introduce further complexity into the reflex arc described by James. Far from being considered as automatic responses to stimuli, the bodily movements seem to be endowed with the capacity of interpretation and cognition. This last aspect is probably the most innovative and enables the development of a pragmatist approach to the rationality of emotions. To a certain extent, Peirce stays close to the etymology of the word e(x) motion. In certain circumstances when we are overwhelmed by an emotion, we may be paralyzed and reduced to silence, but more often than not emotions push us into action. It would be very artificial to separate the feeling of being scared from the different sensations attached to the experience of being scared such as shaking, going pale, feeling one's heart beating faster, as well as the different solutions that we find to protect ourselves or to face, or even escape from the danger. According to the three dimensions of the dynamic interpretant, we can actually identify the three categories of Firstness, Secondness, and Thirdness, but instead of being separated, they appear as a part of the same process, embedded within the situation. Frequently, the process of the dynamic interpretant of an emotion develops not within a single individual but in a situation where several individuals are communicating and adjusting to each other. The sign of the quality of an emotion felt by A can also be the source of an energetic and logical interpretant for B and in return, what is felt by B can be the source of new interpretants from A or from other individuals involved in the situation ad infinitum. This leads to the conclusion of Paul Kockelman's study of agency: "Most so-called emotions may be decomposed into a bouquet of more basic and varied interpretants, and the seemingly most subjective forms of experience may be reframed in terms of their public, intersubjective effects" $(2007,379) .{ }^{5}$ Not only can we say that emotions are not direct reactions to perceptions and that they are not pure inner subjective feelings, but we can also maintain that they play a decisive role in human interactions, as a means to interpret and evaluate and adapt social conduct.

\section{Emotions as Hypotheses}

Emotions are not fixed once and for all, they are the result from "bouquets" of sensations, bodily movements and physical reactions gathered into one single predicate such as joy, melancholy, or anxiety etc. 
This predicate is actually hypothetical.

\begin{abstract}
The emotions, as a little observation will show arise when our attention is strongly drawn to complex and inconceivable circumstances. Fear arises when we cannot predict our fate; joy in the case of certain indescribable and peculiarly complex sensations. If there are some indications that something greatly for my interest, and which I have anticipated would happen, may not happen; and if, after weighing probabilities, and inventing safeguards, and straining for further information, I find myself unable to come to any fixed conclusion in reference to the future, in the place of that intellectual hypothetic inference which I seek, the feeling of anxiety arises. When something happens for which I cannot account, I wonder. When I endeavor to realize to myself what I never can do, a pleasure in the future, I hope. "I do not understand you," is the phrase of an angry man. The indescribable, the ineffable, the incomprehensible, commonly excite emotion; but nothing is as chilling as a scientific explanation. Thus an emotion is always a simple predicate substituted by an operation of the mind for a highly complicated predicate. Now if we consider that a very complex predicate demands explanation by means of a hypothesis, that that hypothesis must be a simpler predicate substituted for that complex one; and that when we have an emotion, a hypothesis, strictly speaking, is hardly possible-the analogy of the parts played by emotion and hypothesis is very striking. ${ }^{6}(147)$
\end{abstract}

This quotation underlines how emotions are integrated into situations and how they follow the development of each situation until its final conclusion. The insistence on "the ineffable" or "the incomprehensible" reveals to that which point the human beings can be affected by a situation or an event, and can react to it with a transaction which can be an anticipation of the future of the present situation. Actually, two kinds of hypotheses seem at stake for Peirce. Fear, anxiety and hope obviously arise when the future is uncertain or unpredictable. Hope is a rather positive hypothesis when fear and anxiety are more pessimistic. In any case, these emotions are hypotheses concerning an undetermined future. But the analogy between emotions and hypotheses comes also from the fact that some emotions arise when we experience something we cannot describe or account, like joy and wonder. In these cases, the hypotheses concern the present situation rather than its future developments and take part in the process of determination of the situation.

Not only does Peirce say that an emotion results from the gathering of a variety of phenomena under one single predicate like a hypothesis, but he also asserts that emotions are hypotheses. Stanley Harrison summarizes this position by stating that: The significance and originality of Peirce's position is seen in his view that even sensations and emotions are interpretative or representative responses to an object. In short, Peirce develops the position that "a sensation is not... (a) first impression of sense" (C.P. 5.291), but the result of a combination of more complex impressions originating in the sense organs. A sensation of a certain color, for example, is for Peirce "a simple predicate taken in place of a more complex predicate; in other words, it fulfills the fiction of any hypothesis" (C.P. 5.291). Inasmuch as this occurs spontaneously, a sensation is a "natural mental sign... a predicate of something determined logically by the feelings which precede it” (C.P. 5.292). ${ }^{7}$ Emotions are hypotheses which are composed of sensations which are themselves hypotheses and so on ad infinitum. They fit together in a continuous process. Mental processes thus organize this way the heterogeneity of the various phenomena inferentially. However, the result is never definitely determined because a hypothesis always must be confirmed. Therefore, emotions, sensations, and every mental process are part of a permanent and general inquiry which resolves itself through the interactions between organisms and their environment. Emotions link together the organisms and the situations in which they are engaged or the events which affect them. Emotions link them together through a variety of adjustments as far as they share the same interpretants and the same hypotheses regarding to what is happening to them. These various operations of assembling are compared by Peirce to a piece of music: 
Thus the various sounds made by the instruments of an orchestra strike upon the ear, and the result is a peculiar musical emotion, quite distinct from the sounds themselves. This emotion is essentially the same thing than a hypothetic inference, and every hypothetic inference involves the formation of such an emotion. We may say, therefore, that hypothesis produces the sensuous element of thought. ${ }^{8}$ (2.643)

\section{Emotions as Valuations}

Dewey minimizes the role of inference in emotional activity. To a certain extent, we can say that he articulates both James and Peirce's two theories of emotions in his theory of valuations. This articulation involves a distinction between what he calls simple organic reactions like crying or smiling or taking weight, and the expression of an emotion. For him, the so called bodily expressions do not actually express anything in themselves, but they may be interpreted by an observer as a sign or an evidence of an organic change, and they will give rise to specific behaviors adapted to this new situation in return. The specificity of John Dewey's approach in this context is that he ties together emotions and value propositions which endow emotions with a political importance in democratic political life. On the other hand, if we go back to his premises, we may note that he does not take into account the role of the interpretant before an emotion becomes noticeable for an observer who can then consider it as an indice. It seems as if, in his focus on social interactions, Dewey fails to include in his account individual's capacity to determine or identify their own emotions, as part of their inner life, because emotions in this sense are not noticeable to an observer. Being reproduced conventionally, a bodily change, as an indice, becomes a linguistic sign, a symbol. But he gets around a great deal of the Peircean demonstration which emphasizes the fact that conventional and therefore linguistic signs are only a particular type of signs. If emotional signs can be reproduced and used conventionally, this is because they are also indices and to communicate something, i.e., to give evidence of something, and they need to be ruled by the same interpretant for the individual who is experiencing an emotion and for the observer. It is only possible for someone else to notice that I feel indignant if we share a common interpretant for indignation. For Peirce, the interpretant is social because it is held in common. Shared interpretants build a bridge and create continuity between the inner life and the social life which otherwise would be so separated that we would be unable to communicate with one another. Of course, nothing guarantees that I am actually feeling the same way as somebody else when we are both saying that we feel indignant, but there must be something in common which makes us gather a manifold of equivalent signs into a similar "piece of music." Interpretants regulate our inner life in a social manner which allows us to communicate with others. This argument leads to the conclusion that if a particular group of people or let say a public, feels indignant, this is not the result of some kind of contagion, but rather occurs because they share a common interpretant of what they are feeling with regard to a specific situation and that this common interpretant is a value proposition on the situation which points in the direction of the conditions in which their common indignation originates.

\section{Medias and the Sharing of Situations from Distance}

What are the consequences of a pragmatist approach to emotions in media studies? The fact that emotions can be intentionally produced as a sign in order to give rise to a certain reaction is important with regard of the media coverage of collective events. For instance, the display of the victims of the tsunami in Asia in 2004 played a crucial role in the raising of funds to help affected populations in Indonesia and Thailand. On the contrary, the solidarity movement which arose in India, a country which refused international help, got very little coverage in the French media. More often, media coverage of the victims of a conflict becomes an 
argument that both sides of the conflict use to put pressure on the viewing public. In any situation both the journalists and the public face the task of uncovering the intentions which give rise to certain emotional signs. In this respect, the media's display of emotional signs often has a double orientation: to give rise to a certain response from the public or from governmental or non-governmental institutions and to reveal or denounce the conditions in which these emotional signs originated, but it can also criticize the intentions supposed to be hidden behind the display of the emotional signs. For instance, the first videos showing US prisoners of war in 2003 were denounced by US Defense Secretary Donald Rumsfeld as pure propaganda when Al Jazeera argued that the videos were an evidence and a disclosure of the existence of prisoners.

The rise of collective emotions has an impact on the situations in which a collectivity is engaged: first, as value propositions on the situation, then through the development of the dynamic interpretants which rule collective agency as Kockelman says, and lastly because the situation actually develops through interactions. An interesting example is the coverage of Mubarak's resignation in February 2011 and the Egyptian people gathered in Tahrir Square at the same time. Most television networks around the world (ABC, Al Jazeera, France 2 etc.) portray this sequence ${ }^{9}$ of events through two shots: one of the speech of Omar Suleiman, Mubarak's spokesman, and the other of Egyptians loudly expressing their joy in Tahrir Square. These filmed sequences show the joy of the people on the square as if it were a direct response to the official announcement. But a video found on Youtube tells a different story. First after weeks spent awaiting Mubarak's resignation, it seemed that the people in Tarhir Square had lost hope and were not expecting such an announcement on that very day and this was important to understand the sudden burst of joy of the population as a real achievement of the situation. Also, it was a Friday and many prayers were addressed to god for Mubarak's resignation. This was especially the case given that the announcement was broadcast during the afternoon prayer. This particular situation led many to perceive the resignation as a gift from God. Different emotions followed upon each other, from the beginning of the prayer to the celebration of victory, in which fervor met with joy and a feeling of popular unity. While most of the media narrations of scenes of jubilation in the square as the "joy of the Egyptians when they heard the news," this amateur video showed that most of the people on Tahrir Square were not able to witness the news from the television, first because there were very few televisions present, and second because as many were praying at the time, they had to wait to finish their prayers before raising their arms, screaming, jumping, dancing etc. In fact, these so-called "expressions of emotion” actually reacted to a change in the collective conditions of the Egyptian people and transformed the long weeks of expectation and combat into a victory and probably a unique moment of grace. On the Internet, a flow of greetings and comments flowed in from around the world, most saying that on this special day "We are Egyptians." The existence of shared interpretants made it possible for people who were far away to share the situation from a distance. This is not to say that interpretants are universal, since on the contrary they are based on habits, rules, and culture, and there are enough cases of situations which are impossible to share worldwide or which simply cannot be understood to prove that in the sharing of situations from a distance as on any other occasion, interpretants are cultural. In this respect, the joy of the people may have been a more acceptable description of the situation for most of the television networks than the religious fervor.

The video illustrates various aspects of the process of emotions described by Peirce. The people were affected by the announcement of Mubarak's resignation and their reactions actually performed a victory as a transaction between a plurality of organisms and a situation. The joy of the activists achieved the victory. Also, their emotions were not immediately determined. Facing "complex and inconceivable circumstances," the 
people on Tahrir Square experienced several different emotions which gradually developed into one single manifestation of joy. The people manifested their joy to each other through different bodily movements. Far from being consensual or contagious, these manifestations had to take into account the disagreement of other supports of Mubarak's resignation wanting to wait till the end of the Friday prayer. When addressed to the viewers on the TV networks and on the Internet, the manifestations of joy were also performing a public in the sense of Dewey. Beyond the activists gathered in Tahrir Square joined by the people of Cairo, the Egyptians and Egypt could appear visually as one collective entity unified by the same feeling of joy.

\section{Notes}

1. James, William, “What Is an Emotion?” Essays in Psychology Vol. 11. 1983. Originally published in Mind 9 (April 1884): 188-205.

2. Savan, David, “Peirce’s Semiotic Theory of Emotion.” Proceedings of the C.S. Peirce Bicentennial International Congress. Eds. Kenneth L. Ketner, Joseph M. Ransdell, Carolyn Eisele, Max H. Fisch, and Charles S. Hardwick, 319-33. Lubbock: Texas Tech University Press, 321.

3. Peirce, Charles Sanders, 5.292.

4. Savan, David, op.cit. "An Introduction to CS Peirce’s Full System of Semeiotic.” Monograph Series of the Toronto Semeiotic Circle, n 1, Toronto (1987-1988), 48, quoted by R. Beeson.

5. Kockelman, Paul, “Agency, the Relation between Meaning, Power and Knowledge.” Current Anthropology Vol. 48, Number 3, June 2007, 379.

6. Peirce, C.S., 5.292, 147.

7. Harrison, Stanley, "Peirce on Persons.” Proceedings of the C.S. Peirce Bicentennial Congress. Eds. Kenneth L. Ketner, Joseph Ransdell, and Carolyn Eisele, 217-21. Lubbock: Texas Tech University Press, 1981, 145.

8. Pierce, C.S., 2.643.

9. Arquembourg, Jocelyne, "The Collective Sharing of Emotions, from Contagion to Communication, a Pragmatist Approach.” Arquembourg,J., Aranguren, M., Doing things with emotions, Paris, Information in Social Sciences, 2015.

\section{Works Cited}

Aranguren, Martin and Tonnelat Stephane. "Coping with Crowdedness in Mass Transportation. The Role of Emotions in the Paris Metro.” Metropolitics.eu. 2014.

Arquembourg, Jocelyne. "Des images en action, Performativité et espace public.” Réseaux 163, Un tournant performatif, ce que "font” les mots et les choses, dir. C. Licoppe. Paris, 2010.

---. “Sharing Emotions from a Distance.” Information in Social Sciences. Paris: EHESS, to be published.

Beeson, Robert. Peirce on the Passions, the Role of Instinct and Emotion in Inquiry and Action. University of South Florida, 2008.

Dewey, John, “Theory of Valuation.” International of Unified Science, 4 Vol. II. Chicago: The University of Chicago Press, 1939. 1-67.

---. “The Objects of Valuation.” The Journal of Philosophy, Psychology and Scientific Method, 10 Vol. XV. 1918. 253-8.

---. La formation des valeurs. Translated and presented by Alexandra Bidet, Louis Quéré, Gérôme Truc. Paris: La Découverte, 2011.

Harrison, Stanley. "Peirce on Persons.” Proceedings of the C.S. Peirce Bicentennial Congress. Eds. Kenneth L. Ketner, Joseph Ransdell, and Carolyn Eisele. Lubbock: Texas Tech University Press, 1981. 217-21.

James, William. “What Is an Emotion?” Essays in Psychology, Mind 9 (1884): 188-205. New edition, The Works of William James Vol. 11. 1983.

Kant, Emmanuel. Fondements de la métaphysique des mœurs. Paris: Delagrave, 2005 (original work published in 1785).

Kockelman, Paul. “Agency: The Relation between Meaning, Power, and Knowledge.” Current Anthropology 48.3 (2007): 375-401.

Lebon, Gustave. Psychologie des Foules (1895). New edition. Paris: Presses universitaires de France, Collection "Quadrige,” 1988. 
Livet, Pierre. Emotions et rationalité Morale. Paris: PUF, 2002.

Niedenthal Paula, Krauth-Gruber Silvia, and RIC François. "Psychologie des Individus, Groupes, Cultures.” Comprendre les émotions. Perspectives cognitives et psycho-sociales. Mardaga: coll., 2009.

Nussbaum, Martha. “Les émotions comme jugements de valeur.” Raisons Pratiques 6. Paris: EHESS, 1995.

Paperman, Patricia. “L’absence d’émotion comme offense.” Raisons Pratiques 6. Paris: EHESS, 1995.

Peirce, Charles Sanders. Collected Papers of Charles Sanders Peirce, 8 volumes; Vols. 1-6. Eds. Charles Hartshorne and Paul Weiss. Cambridge: Harvard University Press, 1931-1935; Vols. 7-8. Ed. Arthur Burks. Cambridge: Harvard University Press, 1958. (References to writing in Collected Papers of Charles Sanders Peirce are quoted in the standard form: the volume in Arabic numerals, a period, and the paragraph in the volume cited.)

Savan, David. "Peirce's Semiotic Theory of Emotion.” Proceedings of the C.S. Peirce Bicentennial International Congress. Eds. Kenneth Ketner, Joseph Ransdell, Carolyn Eisele, Max Fisch, and Charles Hardwick, 319-333. Lubbock: Texas Tech University Press, 321.

Smith, Adam. Théorie des sentiments moraux, 1759. Trad. Michaël Biziou, Claude Gautier et Jean-François Pradeau. Paris: PUF, coll. “Quadrige,” 2011. 